\title{
LncRNA gadd7, increased in varicocele patients, suppresses cell proliferation and promotes cell apoptosis
}

\author{
Jun Zhao ${ }^{1, *}$, Huan $\mathrm{Li}^{1,{ }^{*}}$, Hao Deng ${ }^{1, *}$, Li Zhu ${ }^{1, *}$, Bingyu Zhou ${ }^{1}$, MeiQiong Yang ${ }^{1}$, \\ QianRu Liu ${ }^{1}$, GuoQun Luo ${ }^{1}$, Yunxia Yang ${ }^{1}$ and WenMin Ma ${ }^{1}$ \\ ${ }^{1}$ Assisted Reproductive Technology Center, Foshan Maternal and Child Health Care Hospital, Foshan, China \\ *These authors are contributed equally to this work
}

Correspondence to: Huan Li, email: 421991218@qq.com

Keywords: gadd7; varicocele-related sperm impairment; male infertility

Received: October 13, $2017 \quad$ Accepted: October 30, $2017 \quad$ Published: November 24, 2017

Copyright: Zhao et al. This is an open-access article distributed under the terms of the Creative Commons Attribution License 3.0 (CC BY 3.0), which permits unrestricted use, distribution, and reproduction in any medium, provided the original author and source are credited.

\section{ABSTRACT}

Varicocele-related sperm damages are usually caused by oxidative stresses. Growing evidence indicates that IncRNA growth arrested DNA-damage inducible gene 7 (gadd 7 ) is involved in the regulation of the oxidative stress responses. In this study, we measured the expression level of gadd7 in the sperm and found that the expression of gadd7 was significantly up-regulated in patients with varicocele compared with the healthy control. The relative expression level of gadd7 was negatively correlated with the sperm count. Overexpression of gadd7 suppressed cell proliferation and promoted cell apoptosis in mouse spermatocyte-derived cell lines GC-1 and GC-2. Furthermore, the protein level of Bax was raised while $\mathrm{BCl} 2$ expression was reduced after overexpression of gadd7. This work provides a potential novel insight for the varicocele-related sperm impairment and male infertility.

\section{INTRODUCTION}

Infertility is considered a widespread public health problem and nearly half of infertility is caused by a male factor [1]. A varicocele might be noticed as a soft lump, which is an abnormal enlargement of the pampiniform venous plexus in the scrotum [2]. It is thought to result from abnormalities of the veins inside the testicles, leading to a backup of blood that cannot flow, which in turn causes swelling. About $15 \%$ of men in the general population have varicocele, while more than $40 \%$ of male infertility cases showed varicocele [3]. Varicocele may be one of the main contributors in male infertility due to the increased temperature and oxidative stress in scrotum [4]. Although the concept that a varicocele causes male subfertility has been around for more than 50 years now, the mechanisms by which a varicocele would destroy fertility have not yet been satisfactorily explained. Many genetic and epigenetic changes are found to be associated with varicocele-mediated male infertility
[5], but the molecular pathological process is still far from understood. Therefore, a better identification of the biological markers of the male infertility is crucial, especially non-coding RNAs, as their gene expression pattern and function is not very clear.

Long non-coding RNAs (lncRNAs) are a class of non-coding RNAs that play critical functions in cellular response to stressful conditions [6]. Some lncRNAs were strongly up-regulated in the induction of oxidative stress by hydrogen peroxide treatment [7]. Deregulated IncRNAs have generated great interest in diagnosis and therapy for male infertility. Numerous studies focus on the complex network of lncRNAs and proteins in regulation of oxidative stress [8]. For example, lncRNA growth arrested DNA-damage inducible gene 7 (gadd7) binds to TAR DNA-binding protein (TDP-43) and promotes its dissociation from cyclin-dependent kinase 6 (Cdk6) mRNA, thus leading to degradation of Cdk6 mRNA [9]. Since Cdk6 is a key factor in the regulation of $\mathrm{G} 1 / \mathrm{S}$ transition of the cell cycle, gadd7-mediated 
regulation contributes to the oxidative stress-mediated cell death.

Based on these previous results, we selected gadd7 as the possible marker for varicocele-mediated male infertility. We hypothesized that gadd 7 may reduce cell proliferation and promote apoptosis.

In the present study, the expression patterns of gadd7 in the ejaculated spermatozoa of patients with varicocele were investigated by using Real-Time qPCR. Cell proliferation and apoptosis were measured after overexpression of gadd7 in the mouse germ cell lines GC-1 and GC-2. To the best of our knowledge, this is the first report showing the expression of gadd7 in varicocele-mediated male infertility and its potential functional roles.

\section{RESULTS}

\section{Semen analysis}

As shown in Table 1, the basic characteristics among varicocele grade II, varicocele grade III and healthy control group are comparable. No differences were noted in the mean age, volume, and $\mathrm{pH}$ among the three groups. However, the sperm count, motility, and vitality were significantly decreased in the varicocele groups. These sperm parameters were further decreased in the varicocele grade III group, suggesting that patients with varicocele have abnormal spermatogenesis and poor semen quality. The spermatozoa were then purified for RNA extraction and Real-Time qPCR.

\section{gadd 7 was up-regulated in the spermatozoa of patients with varicocele}

Since oxidative stress is one of the two major reasons for the varicocele-related spermatogenesis damage, we measured the expression of gadd7 which was reported to be involved in oxidative cellular stress. The relative expression levels of gadd 7 were determined using Real-Time qPCR in a total of 56 patients with varicocele and 28 healthy controls. As shown in Figure $1 \mathrm{~A}$, gadd7 was up-regulated in varicocele groups compared to normal control group. The expression of gadd 7 in the ejaculated sperm revealed significant increase in patients with varicocele grade III compared with varicocele grade II group. The relative expression level of gadd7 was negatively correlated with the sperm count (Figure 1B). Therefore, we investigated the functional roles of gadd7 in the following study.

\section{Overexpression of gadd 7 inhibited cell proliferation}

Mouse germ cell lines GC-1 and GC-2 were transfected with either pcDNA3.1-gadd7 or negative control plasmid and cultured in normal medium. Fortyeight hours after transfection, the cells were collected. Then the gadd7 expression levels in pcDNA3.1-gadd7 or negative control plasmid transfected cells were analyzed. The relative expression levels of gadd7 in GC-1 and GC-2 cells treated with pcDNA3.1-gadd7 plasmids were significantly up-regulated by $22.05 \pm 4.42$ fold and 20.32 \pm 3.59 fold, respectively. Data are presented as the mean \pm standard deviation.

To investigate the possible impact of gadd7 on the proliferation of GC-1 and GC- 2 cells, the cell proliferation was determined by MTT assay. As shown in Figure 2, cell growth inhibition was obtained in GC-1 (Figure 2A) and GC-2 (Figure 2B). Significant differences were demonstrated for all time frames between the pcDNA3.1-gadd7 and negative control plasmid -transfected cells.

\section{Overexpression of gadd 7 promoted cell apoptosis}

To investigate the possible impact of gadd 7 on the apoptosis of GC-1 and GC-2 cells, the cell apoptotic rates of these cells were determined using an Alexa488PI apoptosis detection kit. The results shown in Figure 3 demonstrated that the apoptotic cells (\%) of GC-1 (Figure 3A) and GC-2 (Figure 3B) cell lines transfected with the pcDNA3.1-gadd7 were higher than those transfected with the negative control plasmid.

\section{Overexpression of gadd 7 increased Bax and reduced Bcl2 protein expression}

To investigate the potential bio-markers that induce the above phenotypic changes after overexpression of gadd7, we used western blot assay to determine the protein levels of $\mathrm{Bax}$ and $\mathrm{Bcl} 2$ that are well-known for cell apoptosis. pcDNA3.1-gadd7 significantly upregulated the expression of Bax and down-regulated $\mathrm{Bcl} 2$ at protein levels in GC-1 (Figure 4A) and GC-2 cells (Figure 4B).

\section{DISCUSSION}

LncRNAs are emerging as endogenous triggers of the signaling pathways and play various functions in different human diseases. Recent studies have identified stress-induced miRNAs as potential biomarkers for varicocele [10-12]. These phenomena raise questions about the ability of lncRNAs to induce stress response, since the existing data point to the presence of a complex network of lncRNAs and miRNAs.

gadd7 is a DNA damage-inducible lncRNA, which controls the G1/S checkpoint in response to UV irradiation [13]. gadd7 binds to TDP-43 and promotes Cdk6 mRNA decay. Therefore, gadd7 induces the 
Table 1: Patients and semen characteristics

\begin{tabular}{|c|c|c|c|c|}
\hline \multirow[t]{2}{*}{ Characteristics } & \multirow{2}{*}{$\begin{array}{l}\text { Healthy control } \\
(\mathrm{n}=28)\end{array}$} & \multicolumn{2}{|c|}{ Varicocele } & \multirow[t]{2}{*}{ Pvalue $^{*}$} \\
\hline & & Grade II $(n=35)$ & Grade III $(n=21)$ & \\
\hline Age (years) & $32.32 \pm 3.12$ & $32.35 \pm 3.56$ & $34.46 \pm 3.04$ & 0.356 \\
\hline Volume (ml) & $3.15 \pm 0.52$ & $3.28 \pm 0.85$ & $3.12 \pm 0.47$ & 0.673 \\
\hline $\mathrm{pH}$ & $7.38 \pm 0.12$ & $7.41 \pm 0.24$ & $7.38 \pm 0.32$ & 0.731 \\
\hline Count $\left(10^{6} / \mathrm{ml}\right)$ & $134.21 \pm 65.32$ & $112.42 \pm 52.15$ & $11.08 \pm 4.65$ & 0.009 \\
\hline Percentage of motility & $64.32 \pm 8.41$ & $41.98 \pm 9.43$ & $31.05 \pm 6.98$ & 0.011 \\
\hline Percentage of vitality & $87.45 \pm 9.33$ & $50.14 \pm 11.32$ & $28.80 \pm 7.32$ & 0.008 \\
\hline
\end{tabular}

"P value was calculated using one-way ANOVA. Data are presented as the mean \pm standard deviation.
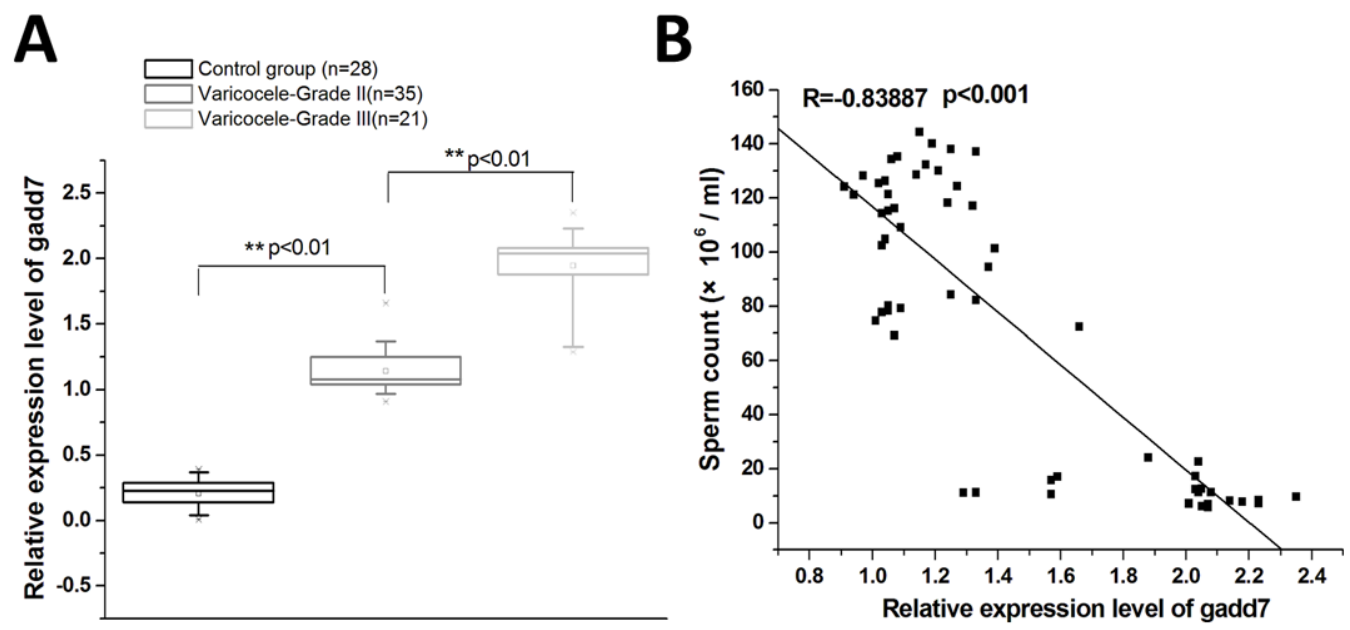

Figure 1: The expression of gadd7 in varicocele and healthy control groups. The relative gadd7 expression levels were determined using Real-Time qPCR. GAPDH was used as an internal control. (A) qRT-PCR analysis of the expression of gadd7 in the ejaculated spermatozoa of varicocele groups or the healthy control. The expression differences were analyzed using independent samples $t$-test. (B) The relative expression level of gadd7 was negatively correlated with the sperm count. Pearson's coefficient correlation was used for expression correlation assay.

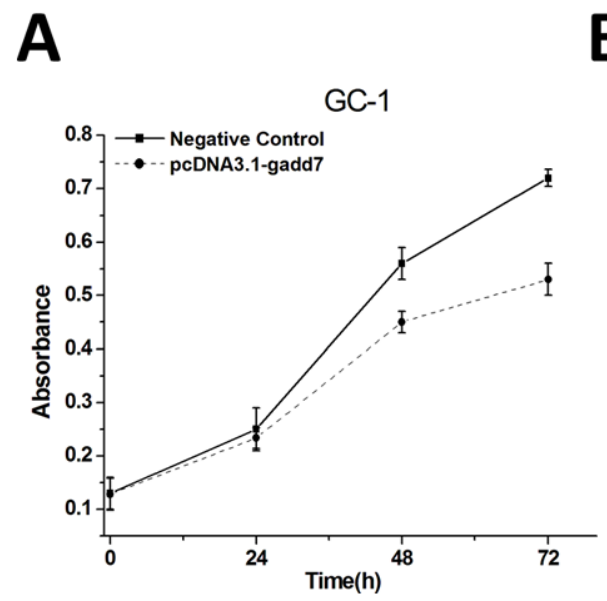

B

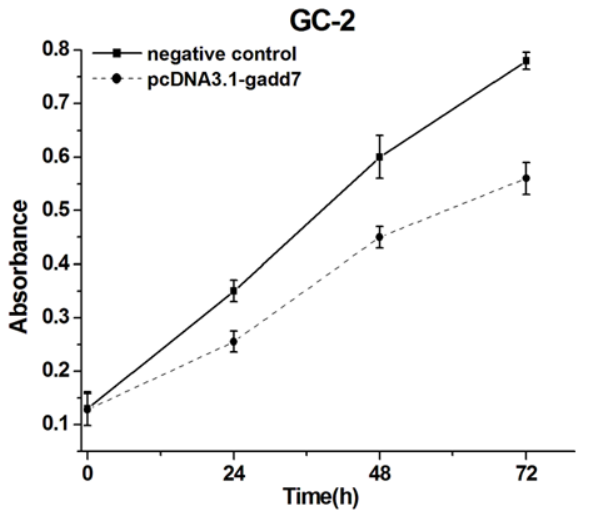

Figure 2: Cell proliferation changes caused by transfection of pcDNA3.1-gadd7. Cell proliferation was measured by MTT assay.pcDNA3.1-gadd7 inhibited GC-1 (A) and GC-2 (B) proliferation. Data are indicated as mean \pm standard deviation. Each experiment in both cell lines was performed in triplicate for three independent times. MTT assays were analyzed using ANOVA. 


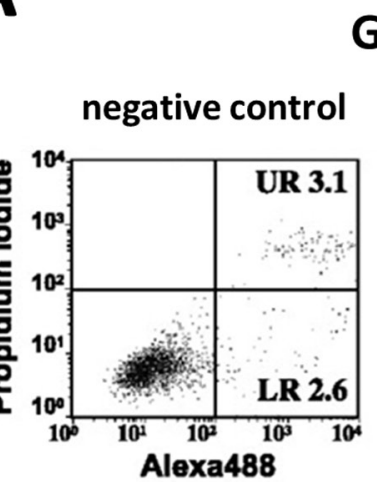

GC-1

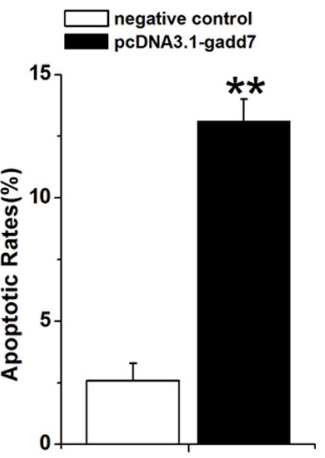

B
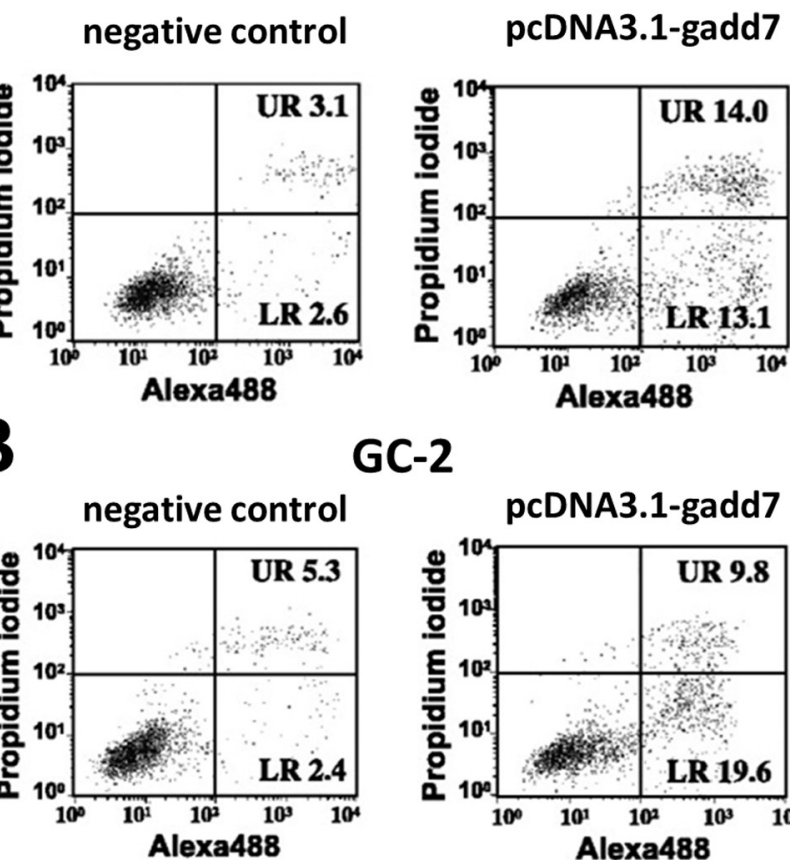

GC-2
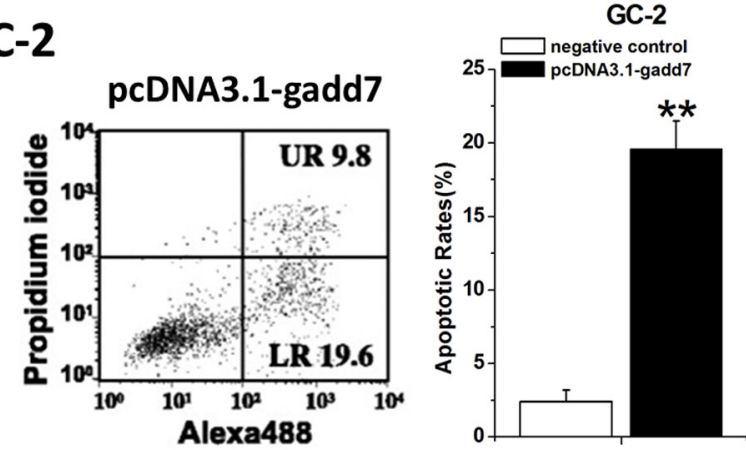

Figure 3: Involvement of gadd7 in cell apoptosis. GC-1 and GC-2 cells were transfected with the plasmids in 6-well plates. Cell apoptosis was measured by the flow cytometry at $48 \mathrm{~h}$ post transfection. Representative images of flow cytometry analysis in GC-1 cells (A) and GC-2 cells (B) were shown. Cell apoptosis induction was observed in pcDNA3.1-gadd7 transfected GC-1 and GC-2 cells using flow cytometry analysis. Error bars, standard deviation. ${ }^{* *} \mathrm{P}<0.01$, compared with the negative control. The apoptosis differences were analyzed using independent samples $t$-test.

A
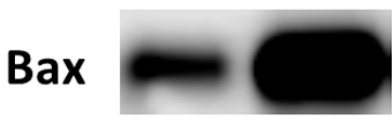

$\mathrm{BCl} 2$
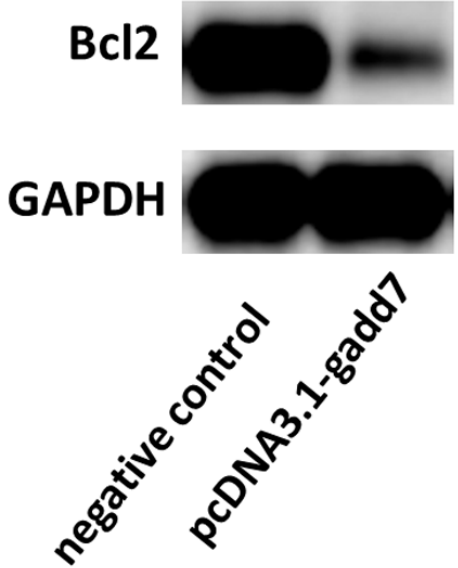

B

GC-2

Bax

$\mathrm{BCl} 2$
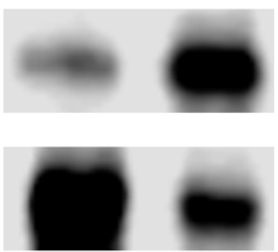

GAPDH
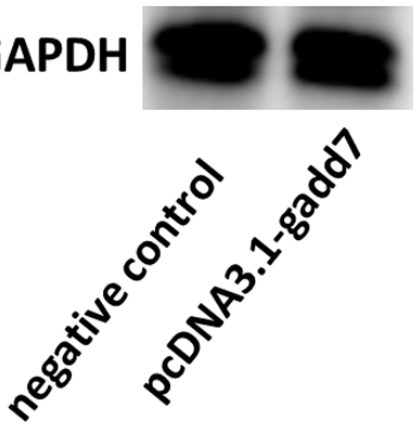

Figure 4: Overexpression of gadd7 increased Bax and decreased Bcl2 protein expression. After transfection of pcDNA3.1gadd7 or negative control, western blot assay was used to detect expression changes of Bax and Bc12 in GC-1 and GC-2 cells. (A) Representative images of western blot assay in GC-1 cells. (B) Representative images of western blot assay in GC-2 cells. 
cellular response to DNA damage and overexpression of gadd7 leads to a decrease in hamster ovary $(\mathrm{CHO})$ cell growth. gadd7 is also found to be a regulator of lipidinduced oxidative and endoplasmic reticulum stress [14]. However, its role in varicocele remains largely unknown.

In the present study, we found that gadd7 was up-regulated in varicocele group compared to normal healthy group. We further hypothesized that gadd 7 may induce sperm impairment. To prove this possibility, we determine the possible impact of gadd7 on $\mathrm{GC}-1$ and GC-2 cells, two commonly used cell lines for studying male infertility. Cell proliferation inhibition and increased apoptosis were observed in gadd7-transfected GC-1 and GC-2 cells. The western blot results suggest that stress-induced gadd7 may lead to cell death and male infertility via upregulating pro-apoptotic regulator Bax [15] and downregulating anti-apoptotic regulator $\mathrm{Bcl} 2$ [16] in varicocele patients. This work provides a potential novel insight for the varicocele-related sperm impairment and male infertility. In future works, the differential expression patterns of gadd 7 may have implications in guiding diagnosis and treatment of varicocele.

\section{MATERIALS AND METHODS}

\section{Clinical sample collection}

56 patients with varicocele and 28 healthy donors with normal semen quality participated in the study. These varicocele sufferers were also infertile patients who had a history of $\geq 1$ year of failed attempts to achieve a pregnancy after regular sexual activity. Exclusion criteria include seminal infection, cryptorchidism, orchitis, testicular atrophy and long-term smoking history. Varicocele was diagnosed according to international clinical classification guidelines: grade I, no visible or palpable distension except when the man performs the Valsalva maneuver; grade II, palpable but not seen; and Grade III, large enough to be visible. A Fresh ejaculate samples were collected from the patients and donors. Normal sperm parameters were defined according to World Health Organization (2010) criteria. The spermatozoa vitality was assessed by hypo-osmotic swelling test according to WHO criteria. The study was approved by the Institutional Review Board of Foshan Maternal and Child Health Hospital (Foshan, China) and written informed consents from all patients were obtained.

\section{Cell lines and cell culture}

The mouse germ cell lines GC-1 and GC-2 were obtained from the Institute of Cell Research, Chinese Academy of Sciences, Shanghai, China. Cells were cultured in RPMI 1640 medium supplemented with 10\% fetal bovine serum (Invitrogen) at $37^{\circ} \mathrm{C}$ in a $5 \% \mathrm{CO}_{2}$ atmosphere.

\section{RNA extraction and real-time quantitative PCR}

Total RNA was extracted from the sperm pellets using TRIzol (Invitrogen) according the manufacture's protocol. RNA was treated with RQ1 RNase-free DNase (Promega) to eliminate genomic DNA contamination and the cDNA strand was synthesized from total RNA with the RevertAidTM First Strand cDNA Synthesis Kit (Fermentas, Hanover, MD). The primer sequences were as follows: gadd7 forward primer: 5'ACAATGACGCCATCGTTTTCT-3', reverse primer: 5'-TGTCCTCCATCTGGGCATTT-3'; GAPDH forward primer:5' -CGCTCTCTGCTCCTCCTGTTC-3', GAPDH reverse primer: -ATCCGTTGACTCCGACCTTCAC-3'. PCRs were set up in a total volume of $20 \mu \mathrm{l}$, including $10 \mu \mathrm{l}$ of Allin-OneTMqPCR Mix (GeneCopoiea Inc., Rockville, $\mathrm{MD}), 0.4 \mu \mathrm{l}$ of forward primer, $0.4 \mu \mathrm{l}$ of reverse primer, $1 \mu \mathrm{l}$ of First-Strand cDNA, $0.4 \mu \mathrm{l}$ of $50 \times$ ROX Reference Dye and $7.8 \mu \mathrm{l}$ of double-distilled water. The reactions were performed in the ABI PRISM 7000 Fluorescent Quantitative PCR System (Applied Biosystems, Foster City, CA). The PCR cycling parameters were: $95^{\circ} \mathrm{C}$ for $15 \mathrm{~min}$, followed by 40 cycles of $94{ }^{\circ} \mathrm{C}$ for $15 \mathrm{~s}, 55^{\circ} \mathrm{C}$ for $30 \mathrm{~s}$ and $72{ }^{\circ} \mathrm{C}$ for $30 \mathrm{~s}$. Expression fold changes were calculated using $2^{-\Delta \Delta \mathrm{Ct}}$ methods.

\section{Plasmid construction and cell transfection}

The gadd7 containing vector (gadd7 overexpression vector driven by CMV promoter) and the control vector (control vector) were purchased from GeneCopoiea Inc, Rockville, MD, USA. pcDNA3.1-gadd7 and the negative control were transfected into cells using Nanofectin ${ }^{\mathrm{TM}}$ Transfection reagent (Excell Bio, Shanghai, China) according to the protocol. The final concentration of plasmid was $1 \mu \mathrm{g} / \mathrm{ml}$.

\section{Cell proliferation assay}

Cell proliferation was measured by 3-[4,5-dimethylthiazol-2-yl]-2,5-diphenyl-tetrazolium bromide (MTT) assay. Cells were grown in a 96-well plate for $24 \mathrm{~h}$, transfected with pcDNA3.1-gadd7 or negative control and cultured in normal medium. Cells were then incubated in $0.1 \mathrm{mg} / \mathrm{ml} \mathrm{MTT}$ at $37^{\circ} \mathrm{C}$ for $4-6$ $\mathrm{h}$ and lysed in dimethyl sulfoxide (DMSO) at room temperature for $10 \mathrm{~min}$ at $0,24,48$, and $72 \mathrm{~h}$ after transfection. The absorbance in each well was measured at $490 \mathrm{~nm}$ by a microplate reader (Bio-Rad, Hercules, CA). Each experiment was done at least three times.

\section{Flow cytometry assay}

GC-1 and GC-2 cells were transiently transfected with plasmid vectors. 48 hours after transfection, cells were harvested and resuspended in fixation fluid. $5 \mu \mathrm{l}$ 
of Annexin V - FIFC and $2 \mu$ of propidium iodide were added to $500 \mu \mathrm{l}$ of cell suspension. Cell apoptosis was then determined by using flow cytometry (EPICS, XL4, Beckman, CA, USA). In the graphs, the quadrant respectively stands for dead cells, living cells, early apoptotic cells and late apoptotic cells.

\section{Western-blot assay}

Cells were lysed in RIPA buffer (50 mM Tris- $\mathrm{HCl}$ pH 7.2, $150 \mathrm{mM} \mathrm{NaCl}, 1 \% \mathrm{NP} 40,0.1 \%$ SDS, 0.5\% DOC, $1 \mathrm{mM}$ PMSF, $25 \mathrm{mM} \mathrm{MgCl2}$, and supplemented with a phosphatase inhibitor cocktail). Lysates from equivalent cell numbers were electrophoresed on SDS-polyacrylamide gels and transferred to PVDF membranes. After blocking with 5\% milk, membranes were incubated with specific primary antibodies (Abcam, Cambridge, MA, USA) against Bax and Bcl2. Then, the blot was incubated with secondary antibody for one hour at room temperature on a rocking platform.

\section{Statistical analyses}

Data analyses were performed by ANOVA or independent samples $t$-test, respectively, using the SPSS (Version 19.0 SPSS Inc.). $\mathrm{P}<0.05$ was considered to be statistically significant.

\section{ACKNOWLEDGMENTS}

We are indebted to the coworkers, whose names were not included in the author list, but who contributed to this work.

\section{CONFLICTS OF INTEREST}

The authors declare that they have no conflicts of interest.

\section{REFERENCES}

1. Jungwirth A, Giwercman A, Tournaye H, Diemer T, Kopa Z, Dohle G, Krausz C. European association of urology guidelines on male infertility: the 2012 update. Eur Urol. 2012; 62: 324-332.

2. Evers JL, Collins JA. Assessment of efficacy of varicocele repair for male subfertility: a systematic review. Lancet. 2003; 361: 1849-1852.

3. Tanrikut C, Goldstein M, Rosoff JS, Lee RK, Nelson CJ, Mulhall JP. Varicocele as a risk factor for androgen deficiency and effect of repair. BJU Int. 2011; 108: 1480-1484.

4. Agarwal A, Hamada A, Esteves SC. Insight into oxidative stress in varicocele-associated male infertility: part 1 . Nat Rev Urol. 2012; 9: 678-690.
5. Zhang Y, Xiao F, Lu S, Song J, Zhang C, Li J, Gu K, Lan A, Lv B, Zhang R, Mo F, Jiang G, Zhang X, Yang X. Research trends and perspectives of male infertility: a bibliometric analysis of 20 years of scientific literature. Andrology. 2016; 4: 990-1001.

6. Özgür E, Mert U, Isin M, Okutan M, Dalay N, Gezer U. Differential expression of long non-coding RNAs during genotoxic stress-induced apoptosis in HeLa and MCF-7 cells. Clin Exp Med. 2013; 13: 119-126.

7. Tani H, Torimura M. Identification of short-lived long noncoding RNAs as surrogate indicators for chemical stress response. Biochem Biophys Res Commun. 2013; 439: 547-551.

8. Giannakakis A, Zhang J, Jenjaroenpun P, Nama S, Zainolabidin N, Aau MY, Yarmishyn AA, Vaz C, Ivshina AV, Grinchuk OV, Voorhoeve M, Vardy LA, Sampath P, et al. Contrasting expression patterns of coding and noncoding parts of the human genome upon oxidative stress. Sci Rep. 2015; 5: 9737.

9. Liu X, Li D, Zhang W, Guo M, Zhan Q. Long non-coding RNA gadd7 interacts with TDP-43 and regulates Cdk6 mRNA decay. EMBO J. 2012; 31: 4415-4427.

10. Anindo MI, Yaqinuddin A. Insights into the potential use of microRNAs as biomarker in cancer. Int J Surg. 2012; 10: 443-449.

11. Ji Z, Lu R, Mou L, Duan YG, Zhang Q, Wang Y, Gui Y, Cai Z. Expressions of miR-15a and its target gene HSPA1B in the spermatozoa of patients with varicocele. Reproduction. 2014; 147: 693-701.

12. Mostafa T, Rashed LA, Nabil NI, Osman I, Mostafa R, Farag M. Seminal miRNA Relationship with Apoptotic Markers and Oxidative Stress in Infertile Men with Varicocele. Biomed Res Int. 2016; 2016: 4302754.

13. Hollander MC, Alamo I, Fornace AJ Jr. A novel DNA damage-inducible transcript, gadd7, inhibits cell growth, but lacks a protein product. Nucleic Acids Res. 1996; 24: 1589-1593.

14. Brookheart RT, Michel CI, Listenberger LL, Ory DS, Schaffer JE. The non-coding RNA gadd7 is a regulator of lipid-induced oxidative and endoplasmic reticulum stress. J Biol Chem. 2009; 284: 7446-7454.

15. Zhang JJ, Zhu Y, Yang C, Liu X, Peng YP, Jiang $\mathrm{KR}$, Miao Y, Xu ZK. Yin Yang-1 increases apoptosis through Bax activation in pancreatic cancer cells. Oncotarget. 2016;7:28498-509. https://doi.org/0.18632/ oncotarget.8654.

16. Um HD. Bcl-2 family proteins as regulators of cancer cell invasion and metastasis: a review focusing on mitochondrial respiration and reactive oxygen species. Oncotarget. 2016;7:5193-203. https://doi.org/10.18632/ oncotarget. 6405 . 